Article

\title{
Analysis and Research on the Node Space of Ancient Villages Based on Space Syntax
}

\author{
Yile Chen ${ }^{1}$ Junzhang Chen ${ }^{2}$
}

1 Macau University of Science and Technology, Faculty of Humanities and Arts Address:Avenida Wai Long, Taipa,Macau,China ; 2009853gat30001@student.must.edu.mo

2 City University of Macau, School of Innovation and Design, Macau SAR, China ; Junzhang Chen , U19091105192@cityu.mo

* Correspondence author: Yile Chen ; 2009853gat30001@student.must.edu.mo

\begin{abstract}
This research takes Cuiwei Village in Qianshan District of Zhuhai City as an example. Through field research, the village is investigated and analyzed, and the street scale, spatial structure, functional characteristic streets, internal commercial distribution forms, and functions of Cuiwei Historic District are studied. analysis. On this basis, based on the convex space method and the line-of-sight analysis method in the space syntax theory, with the help of Depthmap software, the complex street node, that is, the space of the two nodes A and B, is established through the establishment of a visual field model. It includes the analysis of the integration degree of the horizon, the concentration of the horizon, the connection value of the horizon and the spatial characteristics of the historical area, as well as the traditional buildings that are the most representative of the village, namely the Three Kings Temple and the Webster's Mansion. When $\mathrm{R}=\mathrm{N}$ and radius $\mathrm{R}=3$, observe the changes in the two parameters of the visual integration and visual depth of the two historical buildings. And with the help of Baidu Time Machine photos in different periods to observe and record the changes in the store and the characteristics of people's behavior, and draw conclusions.
\end{abstract}

Keywords: Ancient villages; historical locations; node space; convex space method, field of view analysis method, Baidu time machine; parameters

\section{Research scope and research methods}

\subsection{Research scope}

Cuiwei Village is located in the Qianshan area, west of Cuiqian West Road, north of Cuiwei West Road, and south of Renmin West Road. The northwest side is close to the Metro Pearl Station. As one of the largest urban villages in Zhuhai, it has a long history. The old village has an area of 300244.81 square meters. Although there is no unified planning in the early stage of construction, the freedom is greater, the scale itself is relatively large, the building layout is relatively neat, and the craftsmanship of the building itself is very sophisticated, consisting of a group of buildings such as walls, village houses, ancestral halls, and gates.

\subsection{Research methods}

According to the space syntax theory, this paper adopts the horizon model to abstract the space of Cuiwei historical pedestrian street into a syntactic topological relationship, analyzes the spatial form of the block from the perspective of topological geometry, and analyzes the space that pays attention to the historical block of Cuiwei by constructing an axis model. Accessibility and agglomeration can show people more intuitively the spatial morphological characteristics of the block. By constructing a viewshed analysis model, people's perception of the space on the two-dimensional plane can be displayed through the model, which can better analyze the spatial connection between offices. The closeness of. 


\section{Research scope and research methods}

A Horizon integration is to combine the perspective of the crowd to analyze the degree of possibility of being observed by people. It can well reflect the potential in the space. The value can be represented by the color on the map. The warmer the color, it represents the degree of integration of the space. The higher is, the higher the agglomeration coefficient is; on the contrary, the lower. From Figure 80, it can be seen that in the internal streets and lanes of the Cuiwei Village Historic District, the areas with the highest degree of visual integration are concentrated in the street straight street, road A, Renheli, Zhongheli, Dunmuli, Tengfengli entrance, Meisong Wugong The external space of the temple shows that these areas have a high degree of integration of the field of view, and the depth of the global line of sight is relatively shallow, that is, people can see other elements of the space without having to go through many turns, and have good visibility and visibility in the entire space system. Guiding role. Followed by the external space of Cuiwei Street, Dafang Street, Changshui Street, Sanwang Temple, Huishan Wugong Temple, Wu Family Ancestral Temple, Jieweng Wugong Temple, and the Golden Flower Temple, Guandi Temple, The external space of the Caibo Temple shows that the performance of these areas is better, that is, to a certain extent, it can increase the mutual awareness of residents and trigger the exchange of neighborhoods.

From the observation and analysis in Figure 1, it can be seen that the area of road A is easily perceivable by people and is the best area for node space selection. The neighborhood of this street has rich business functions and many residential areas. Outside the residential area is the Industrial and Commercial Bank of China Pearl The actual situation of the road is shown in Table 1 for branches, important consultation rooms of old Chinese medicine doctors, Cuiwei kindergartens, and various types of fast food restaurants. Standing at any place in the road A area, you can clearly see the different business functions. Because the left side of this lot is a two-way four-lane highway on Mingzhu South Road, the road signs of this lot are also clearer and can be observed in a wider range. For the service object, it is more in line with the law of people gathering together. Therefore, when renewing, we should focus on this area, vigorously develop and renovate the business functions around the area, attract developers to invest, develop the western Tanzhou area, and make effective linkage with the renewed Cuiwei Village. 


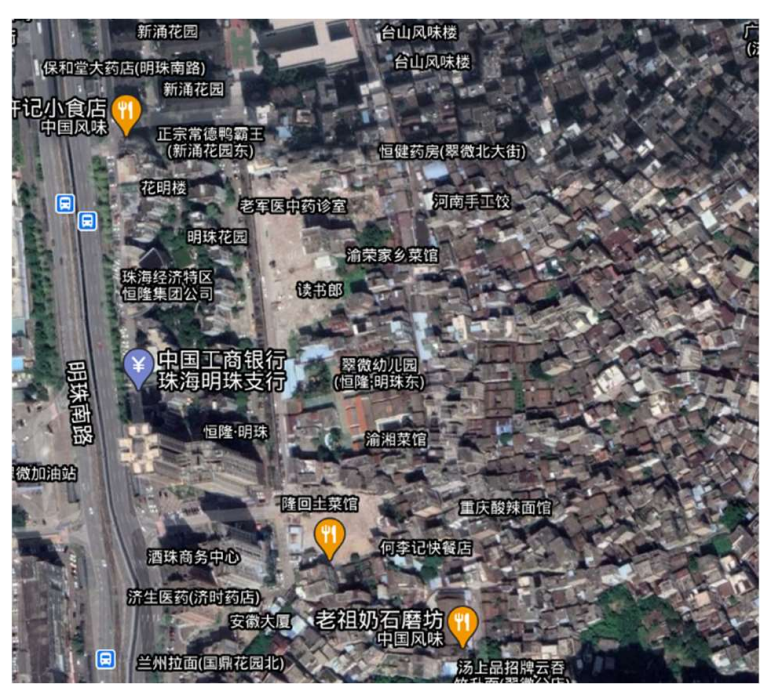

Figure 1 The distribution of road A regional formats Data source: the author draws after intercepting from Baidu map

Table 1 Business Distribution of Road A

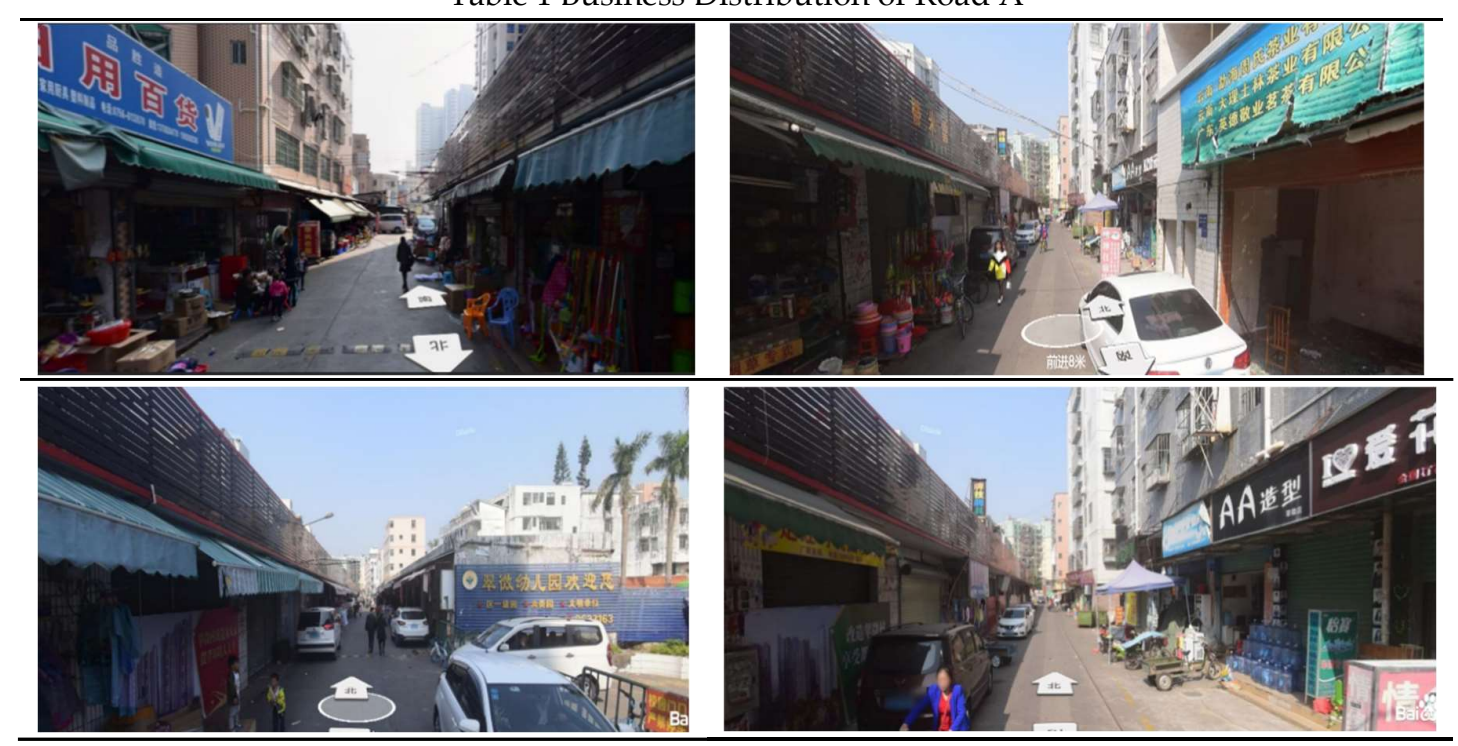

Table source: the author intercepted on Baidu map

Secondly, the street space of the straight street in the market is also highly integrated. As a street that is easy to be perceived, it can be used as an area to focus on the continuation of the function of the main street when the street is upgraded and renovated. When renovating, not only pay attention to the business format near the street. In addition to integration and characteristic shaping, setting up corresponding spatial guidance at entrances and exits with a high degree of integration of the horizon is also a direction worthy of attention. The use of good integration of the horizon can attract more foreign tourists through the update of characteristics, business formats and environment. Reconstruction can better enhance the interest of the space. For the masses outside the block, the block width is not clearly divided in the core block, the overall street style is single, the ground paving is plain soil, concrete, there is no steel reinforcement, and the building is also made of masonry, which is illegal. The construction phenomenon is widespread, and 
it is more difficult for them to infer the functional attributes of other streets and lanes from the spatial scene seen at the intersection of streets and lanes. Therefore, when outsiders build buildings, they will choose plots that have a relatively less narrow field of view and a less narrow space, and neglect the relatively narrow street space, leading to misjudgments in the direction of travel. Some narrow lanes are more tortuous, resulting in increased visual depth and more serious deterioration. Therefore, in the process of street and lane reconstruction and organic renewal, attention should be paid to the application between street and lane intersections, and the commercial facilities at the intersections are increased, as well as signs. , In order to attract more people flow, clarify the direction of people flow, and increase the recognizability of the village. Analyzing the village space by proxy robots, red represents the most number of paths traversed, and blue is the least. From Table 2, it can be seen that the areas with high pedestrian activity in the block are concentrated in Huishan Wugong Temple, Wu's Ancestral Hall and Jie Wengwu The external area of the public ancestral hall, the external area of Jinhua Temple, Guandi Temple, and Caibo Temple; Road A area; followed by Sanwang Temple, Market Straight Street, Cuiwei Street, Dafang Street, Changshui Street, Shengtangli, Webster Outside the mansion The public space and the area at the end of Tunmu-ri show that the flow of people in these areas is high (the space utilization rate is the highest), and the areas with high flow of people are concentrated near the temples, that is, the streets that are connected with the public space, and The main traffic road inside the block, the area outside the block close to the main road, there are often more pedestrian flows, and the rest of the block, except for its own residents, there is less pedestrian flow or even going through it, the activity is small, and the scope is narrow. On the one hand, it is conducive to the formation of a more private living space atmosphere; on the other hand, it is not conducive to the implementation of a mutual supervision mechanism between the masses and functional departments in the neighborhood, and blind spots and blind spots are prone to appear. From the observation in the figure, we can see that there are more "hui"-shaped motion grids in the block. At the same time, the internal "back"-shaped motion network is also easy to serve as a kind of "intermediate form" spatial transition unit, which plays a role in connection. The role of energy flow inside and outside the block.

Table 2 Analysis of the size of the crowd activities in Cuiwei Village

\begin{tabular}{ccc}
\hline Highest flow of people & $\begin{array}{c}\text { The outer area of Huishan } \\
\text { Wu Gong Ancestral Hall, } \\
\text { Wu Family Ancestral Hall } \\
\text { and Jie Weng Wu Gong } \\
\text { Ancestral Hall }\end{array}$ \\
$\begin{array}{c}\text { Outside area of Golden } \\
\text { Flower Temple, Guandi } \\
\text { Temple and Caibo } \\
\text { Temple } \\
\text { volume_up } \\
\text { content_copy }\end{array}$ \\
\hline
\end{tabular}




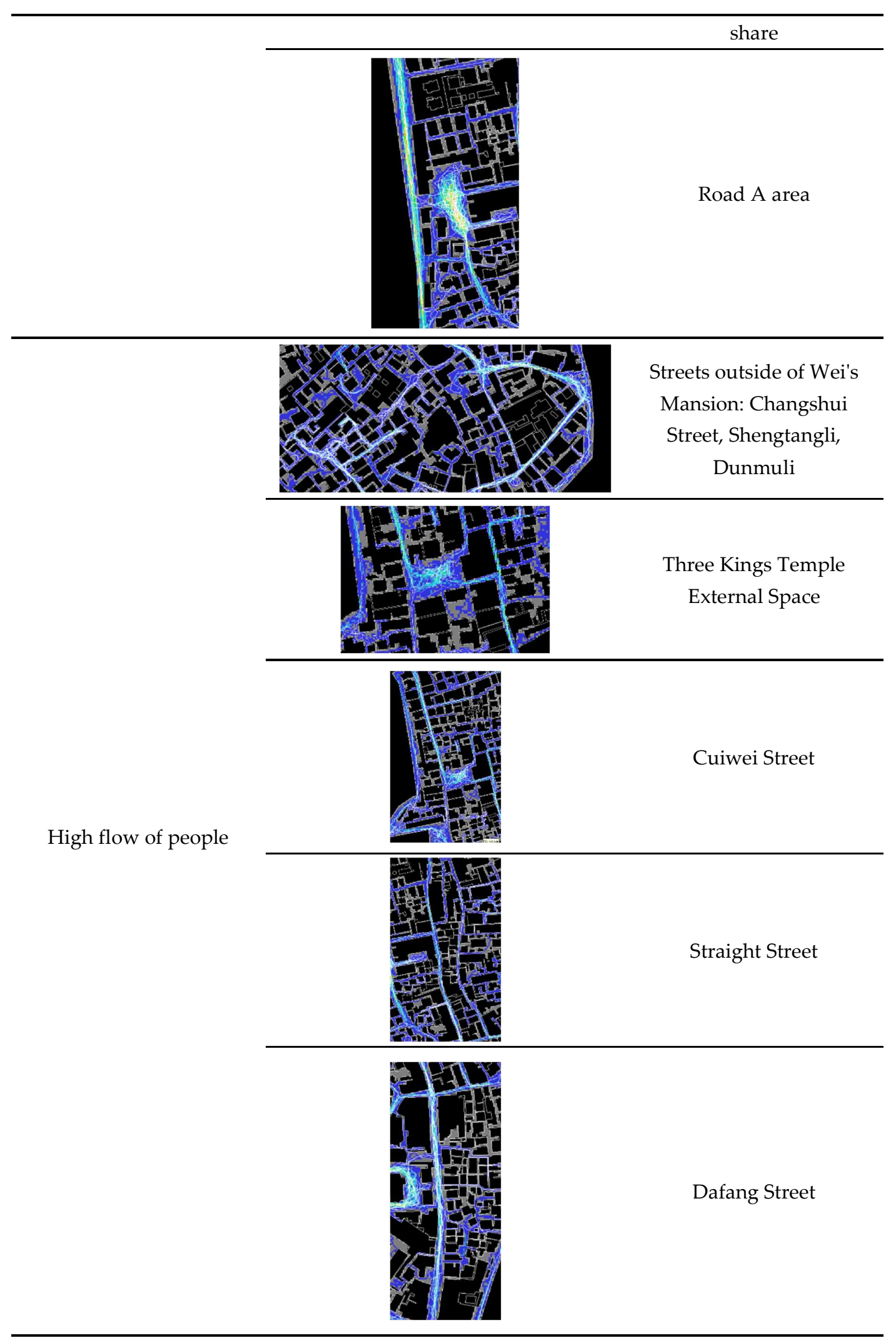

Table source: drawn by the author

2 Interpretation of the Node Spatial Form of the Ancient Village Spatial Form

In the interpretation of the spatial morphology node space syntax of Cuiwei Village block, adopt Convex space analysis is used to cover the entire Cuiwei Village 
system with node A and the immovable historical building Wei-style mansion as the center (Figure 2). Nodes have a strong role in space limitation. Taking each convex space as a space node, draw relation diagrams based on the connection between the plane graph spaces, and calculate the convex space syntactic variables in the entire space system. Including local integration degree, global average depth, local average depth, control value and selectivity of node A and Wei-style mansion. Import the CADprocessed building layers into the Depthmap, calculate the integration degree of the vision through the Horizon Relevance Calculation tab, and observe the areas with darker colors, that is, the areas with higher integration, for the higher agglomeration effect in this area, So more nodes are observed in this area.

\subsection{Quantitative analysis of node $A$ and its surroundings}

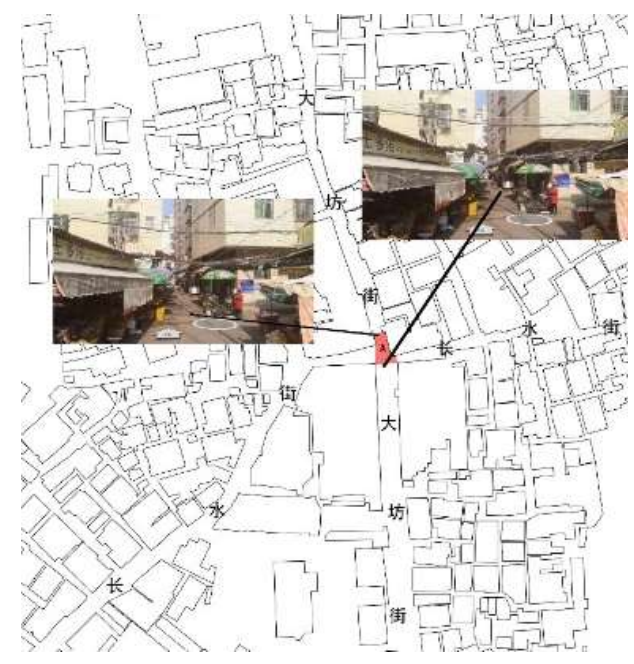

Figure 2 Schematic diagram of node

A Image source: drawn by the author

Node A is located in the important node space inside Cuiwei Historic District, where Dafang Street and Changshui Street meet. There are Jinhua Temple, Guandi Temple, and Caibo Temple on the southwest side of the node. During its heyday, it was an important spatial node in the historical village of Cuiwei. There are many shops on both sides of the road on the south side of the node. There are a large number of stall facilities on the left and right sides of the node, including vegetable stalls and pork stalls. The shopkeepers in the shops are engaged in the textile industry as well as daily necessities. From the actual investigation, the main users of this street are Cuiwei villagers, as well as some local residents and related political personnel in Qianshan. As a direct analysis of the relationship between node $\mathrm{A}$ and the surrounding environment, the convex polygon segmentation is performed to obtain the convex polygon parameter color map (Figure 3-8). 


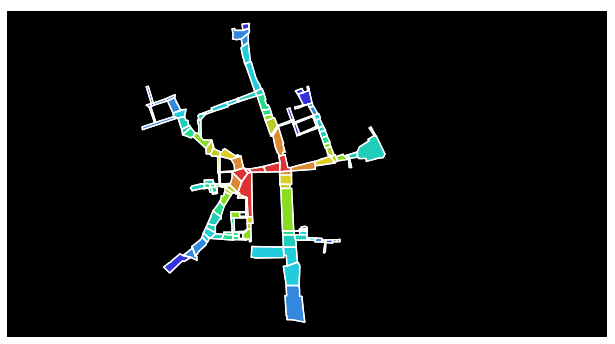

Figure 3 Schematic diagram of the global integration degree of node $\mathrm{A}$

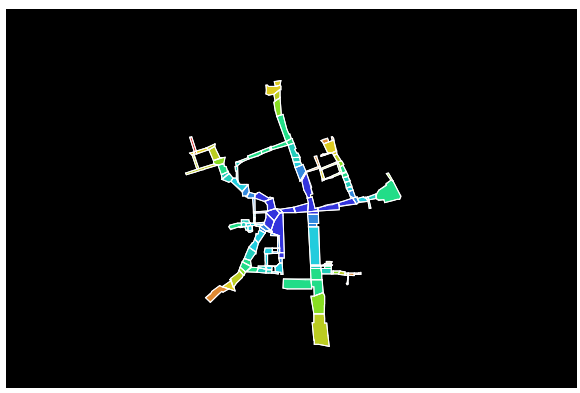

Figure 5 Schematic diagram of the global average depth of node $\mathrm{A}$

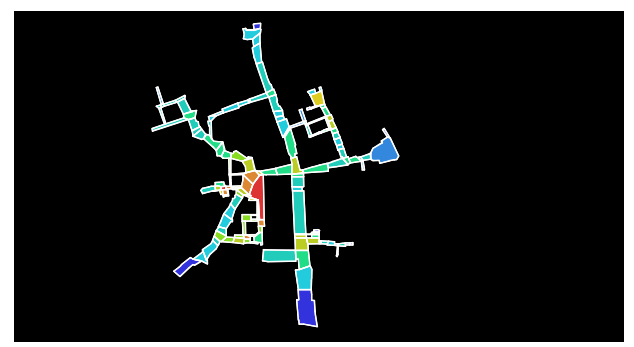

Figure 4 Schematic diagram of local integration of node $\mathrm{A}$

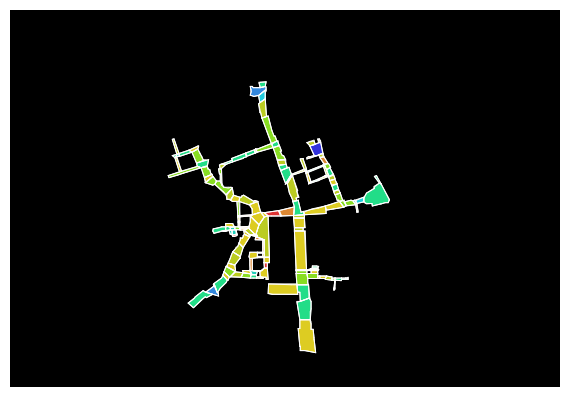

Figure 6 Schematic diagram of the local average depth of node A

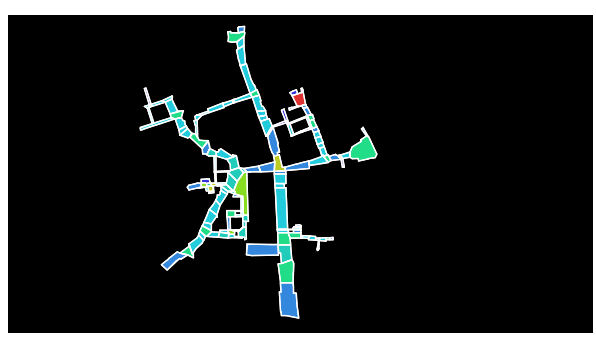

Figure 7 Schematic diagram of the control value of node $\mathrm{A}$

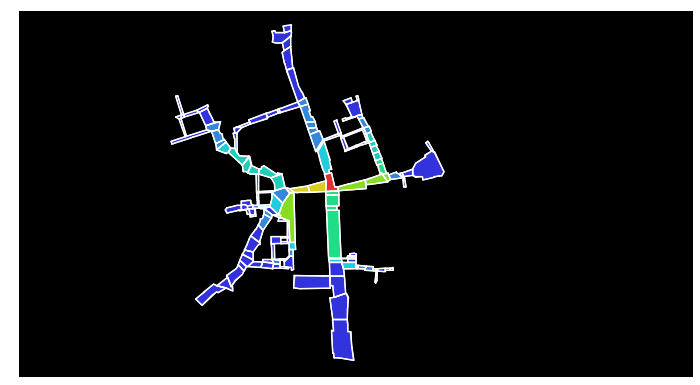

Figure 8 Schematic diagram of node A selection degree

Table source: drawn by the author

By observing the spatial structure where node A is located, it can be seen that the point is centered on A and presents a radial spatial structure. There are also a backshaped structure and an L-shaped structure inside (Figure 9). From the perspective of global integration, node A is red, the L-shaped road connected to it is also red, and the local integration is dark yellow. It can be obtained by constructing the linear equations of the global integration degree and the local integration degree. As shown in Figure 10 , it can be seen that the points are distributed randomly, where $\mathrm{R} 2=0.319$, indicating that the degree of synergy is low, although the two are related The sex is weaker. However, node A is still relatively crowded. As an intersection road, it is an important pivot point in Cuiwei's historical district. Except for the lengthening of the south side, the remaining few are relatively even, indicating that the space is well enclosed and the space feels more intense. More irregular polygons prove that the trend of the integration space in all directions is different. 


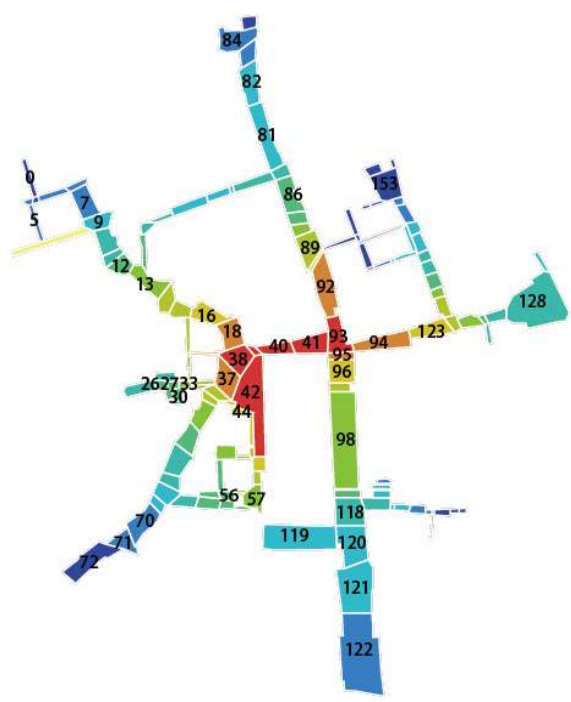

Figure 9 Schematic diagram of segmentation of convex space unit at node A

Image source: drawn by the author

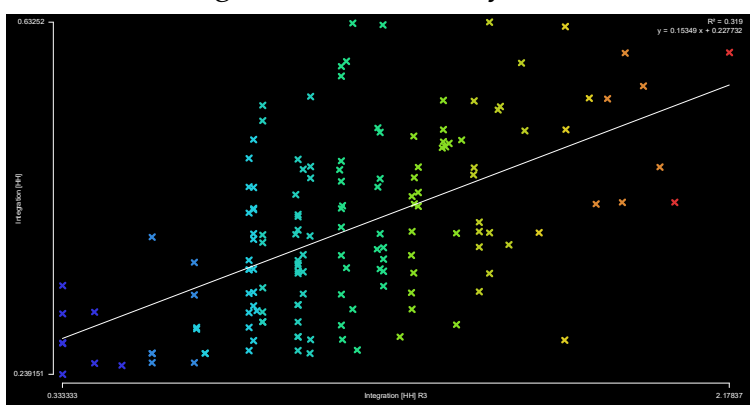

Figure 10 Analysis of the global integration degree and local integration degree of the convex space of node A Image source: drawn by the author

According to the data obtained from the quantitative analysis (Table 3 ), there is a spatial connection value in node A with a maximum value of 7 , which is space NO.42, followed by a connection value of 6 , which is space NO.33, and a connection value of 5, respectively, space NO. .26, NO.27, NO.30, NO.37, NO.38, NO.44, NO.56, the space permeability is relatively good and relatively similar, indicating that the more attractive the space, the greater the potential for traffic, There are more tricycles and cars driving here.

The place with the highest degree of global spatial integration in this lot is NO.93, with a value of 0.63251 . Followed by NO.41, NO.40, NO.39, NO.42, the value is 0.598 0.631. Among them, No. 93 is the junction of Dafang Street and Changshui Street, which is an important turning point and is located in a plot with more crowds. The place with the highest degree of local integration is NO.42, followed by NO.27, NO.33, NO.37, and NO.38, with values ranging from 1.890 to 2.028 .

The area with the highest control value is No. 153, the value is 3 , followed by No. 132, No. 30, indicating that this type of space has a strong dominance over the surrounding space and has a large weight, which can well affect the activities of the villagers in the village. , Node A space is a relatively prosperous section of Cuiwei Historic District. It is the main street in the north-south direction. It has a large flow of people and vehicles and is connected to other lanes. Therefore, there are more people staying here, and the commercial development is better. 
Table 3: Partial parameter table of node A space system

\begin{tabular}{|c|c|c|c|c|c|c|c|}
\hline $\begin{array}{c}\operatorname{Re} \\
\mathrm{f}\end{array}$ & $\begin{array}{c}\text { Choic } \\
\mathrm{e}\end{array}$ & $\begin{array}{c}\text { Connectivit } \\
\mathrm{y}\end{array}$ & Control & $\begin{array}{c}\text { Integration } \\
{[\mathrm{HH}]}\end{array}$ & $\begin{array}{c}\text { Integration }[\mathrm{HH}] \\
\text { R3 }\end{array}$ & $\begin{array}{l}\text { Mean } \\
\text { Depth }\end{array}$ & $\begin{array}{c}\text { Mean Depth } \\
\text { R3 } \\
\end{array}$ \\
\hline 26 & 385 & 5 & $\begin{array}{c}1.783333 \\
3\end{array}$ & 0.39675298 & 1.5154221 & 12.941176 & 2 \\
\hline 27 & 1052 & 5 & $\begin{array}{c}1.316666 \\
7\end{array}$ & 0.43121222 & 2.0276461 & 11.986928 & 1.8666667 \\
\hline 30 & 726 & 5 & $\begin{array}{c}2.116666 \\
6\end{array}$ & 0.43095583 & 1.8828143 & 11.993464 & 1.9333333 \\
\hline 37 & 3692 & 5 & $\begin{array}{c}1.042857 \\
2 \\
\end{array}$ & 0.56060922 & 1.9415878 & 9.4509802 & 2.2592592 \\
\hline 38 & 2874 & 5 & $\begin{array}{c}1.176190 \\
5\end{array}$ & 0.59758264 & 1.8900454 & 8.9281044 & 2.2692308 \\
\hline 39 & 11371 & 4 & $\begin{array}{c}1.092857 \\
1\end{array}$ & 0.62759107 & 1.7257152 & 8.5490198 & 2.3043478 \\
\hline 42 & 8155 & 7 & $\begin{array}{c}1.766666 \\
7\end{array}$ & 0.59807569 & 2.1783681 & 8.9215689 & 2.1428571 \\
\hline 44 & 1919 & 5 & $\begin{array}{c}1.259523 \\
9\end{array}$ & 0.54748315 & 1.7909094 & 9.653595 & 2.2272727 \\
\hline 56 & 1527 & 5 & 1.75 & 0.4289158 & 1.8105773 & 12.045752 & 1.9285715 \\
\hline 93 & 14679 & 4 & 2 & 0.63251984 & 1.5154221 & 8.4901962 & 2 \\
\hline $\begin{array}{c}13 \\
2 \\
\end{array}$ & 606 & 3 & $\begin{array}{c}2.333333 \\
3 \\
\end{array}$ & 0.27740824 & 1.1087778 & 18.078432 & 2 \\
\hline $\begin{array}{c}15 \\
3\end{array}$ & 1202 & 4 & 3 & 0.27730212 & 1.7239312 & 18.084967 & 1.5714285 \\
\hline
\end{tabular}

Table source: drawn by the author

2.2 Quantitative analysis of Webster's Mansion and its surroundings

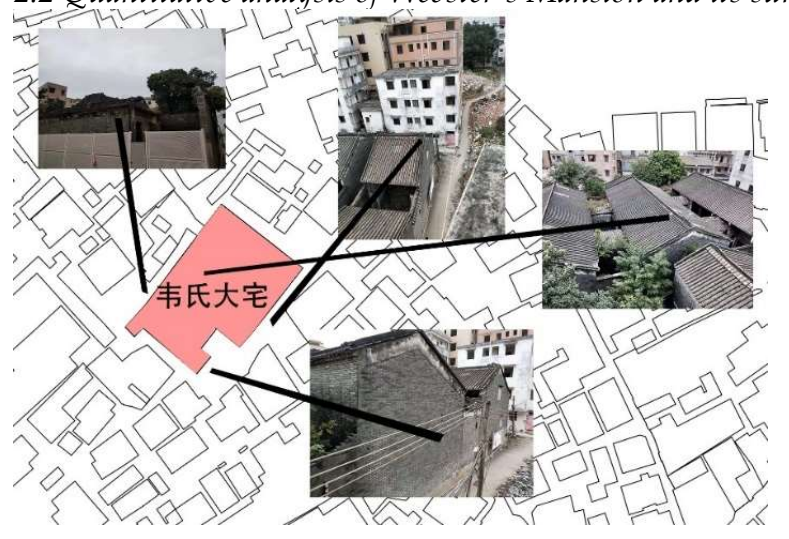

Figure 11 Schematic diagram of Webster's mansion area at Node B Image source: drawn by the author

Webster's Mansion is located in the internal node space of Cuiwei Historic District. The node is located in the northeast of the village. It can be reached from the right side of the back door of Cuiwei Market through Houlongshan Street. The exit on the east side is Cuixian Road. The mansion is surrounded by residential buildings. Dunmuli Street passes by the entrance, and the north side is Zhonghe. In Li Street, it 
was found from the field investigation that the main users of the street are mainly villagers, as well as local residents and related workers in Qianshan (Figure 11).

A direct analysis is made from the relationship between the Webster's Mansion and its surrounding environment within the Cuiwei site. Through the convex polygon segmentation of the part of the Webster's house in the block plan obtained before, the colored analysis diagram of the relevant parameters of the convex polygon is obtained (Figure 12-17).

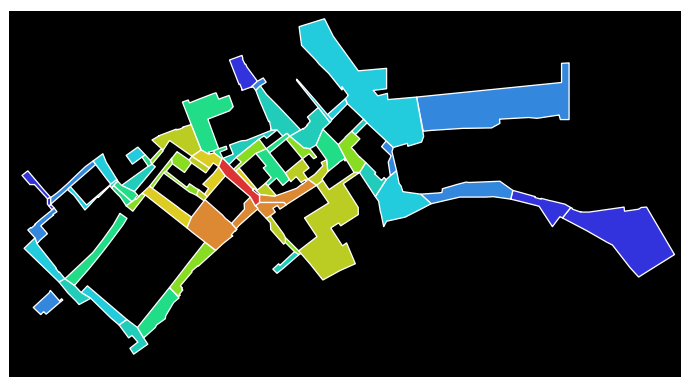

Figure 12 Schematic diagram of the global integration of Webster's Mansion

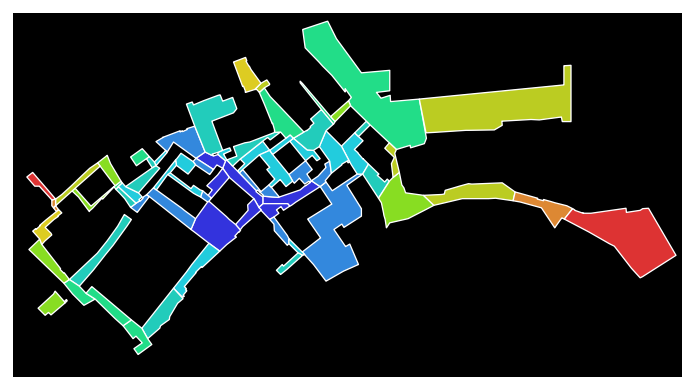

Figure 14 Schematic diagram of the global average depth of Webster House

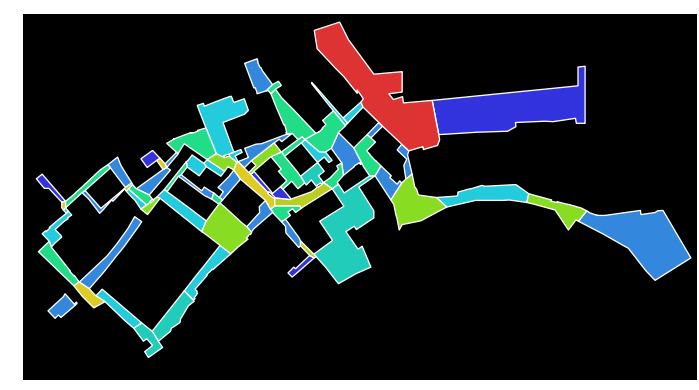

Figure 16 Schematic diagram of the control value of Webster House

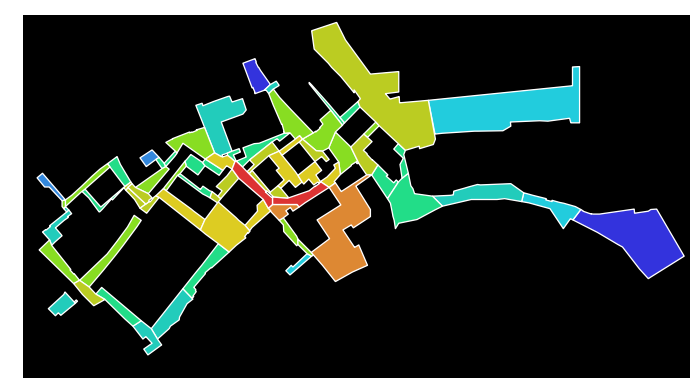

Figure 13 Schematic diagram of the local integration of Webster's Mansion

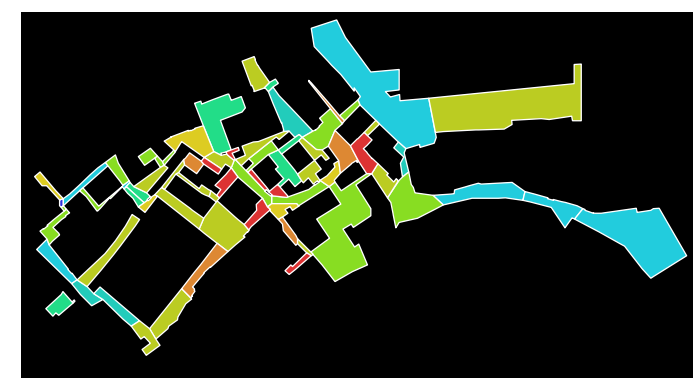

Figure 15 Schematic diagram of the local average depth of Webster's Mansion

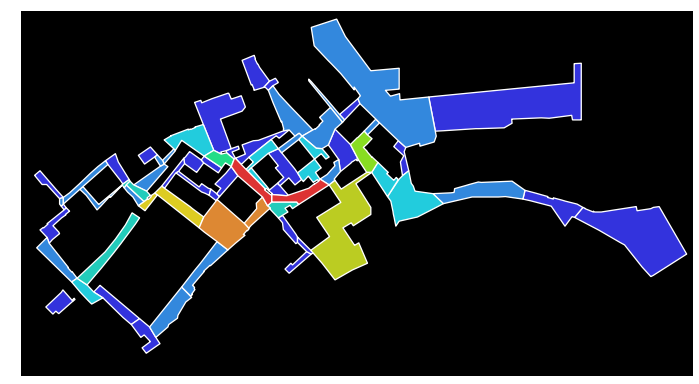

Figure 17 Schematic diagram of the selection degree of Webster's Mansion

Observing the spatial structure of the Webster's Mansion, we can see that it is an irregular structure centered on Webster's space. The internal streets have loops, arcs, and obtuse angle structures. From the global integration, it can be found that node B is red, indicating that the flow of people at node $B$ is relatively dense. According to the field investigation and analysis, it can be found that the location of Node B is located on the east side of Webster's Mansion. The east side is not only red, but also orange and yellow (Figure 18).

Through field investigation and analysis, this is Houshan Long Street, which can lead to the external road of Cuiwei Market, indicating that the large mansion has a large flow of people. The main people come from village residents and residents of the 
Qianshan area who come to Cuiwei Market to buy vegetables. Node B has a small scale in the entire space system, indicating that this space is less enclosed and gives people a weaker sense of space. By constructing global integration and local integration equations, as shown in Table 4, R2 is higher, and with As the value of $\mathrm{r}$ increases and $\mathrm{R} 2$ increases, the point gradually moves closer to a straight line, indicating that as the number of steps increases, the intelligibility is better, where the flow of people and vehicles form good spatial characteristics.

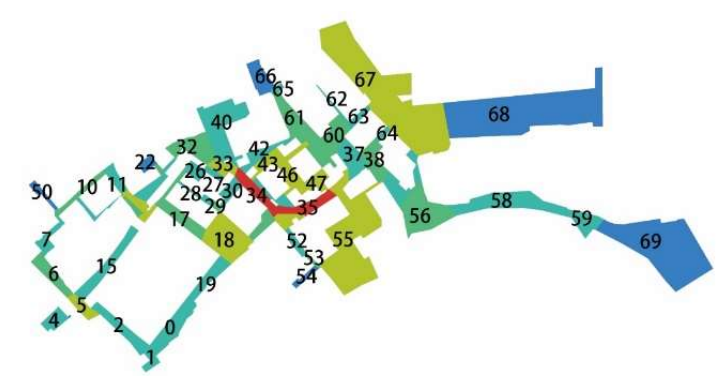

Figure 18 Schematic diagram of segmentation of convex space unit of Webster's Mansion at node B

Image source: drawn by the author

Table 4 R=3,5,7,9 Relationship between global integration degree and local integration degree

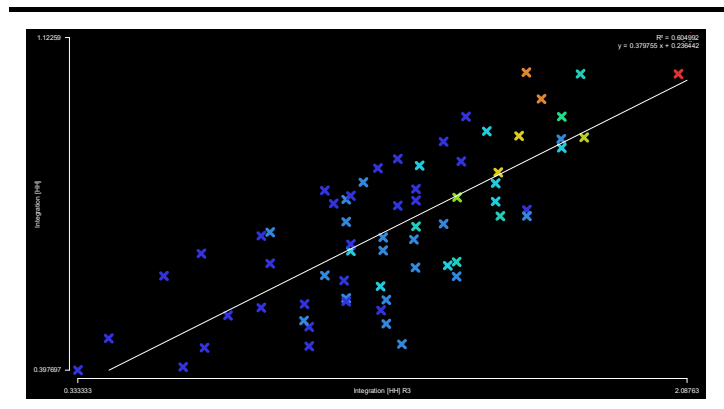

$\mathrm{r}=3, \mathrm{Y}=0.379755 \mathrm{X}+0.236442$

$\mathrm{R}^{2}=0.604992$

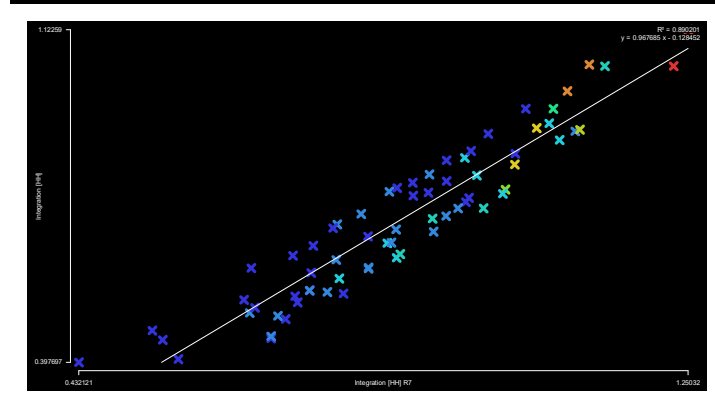

$\mathrm{r}=7, \mathrm{Y}=0.967685 \mathrm{X}+0.128452$

$\mathrm{R}^{2}=0.890201$

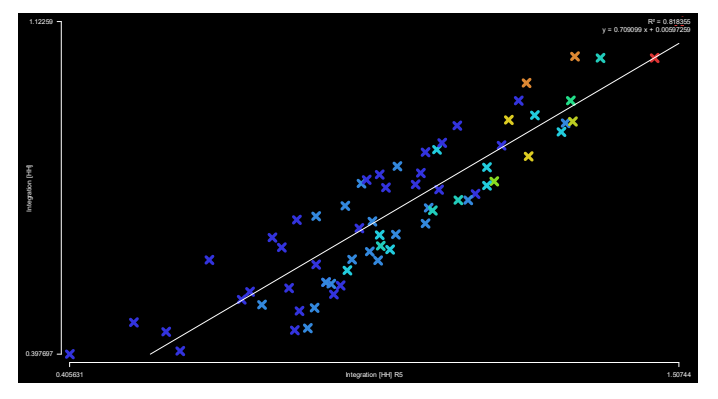

$\mathrm{r}=5, \mathrm{Y}=0.709099 \mathrm{X}+0.00597259$

$\mathrm{R}^{\mathrm{N}}=0.818355$

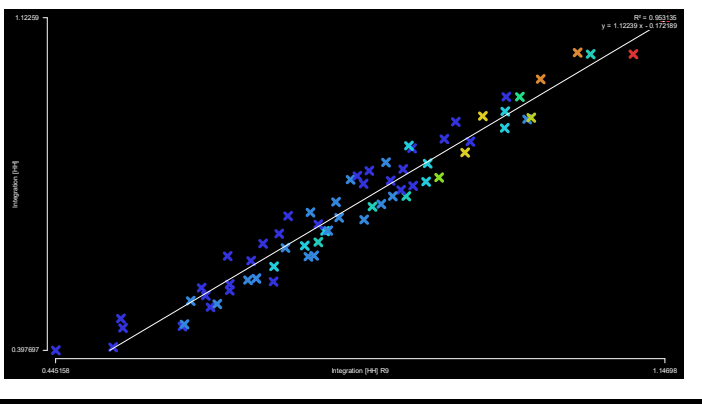

$\mathrm{r}=9, \mathrm{Y}=1.12239 \mathrm{X}+0.172189$

$\mathrm{R}^{2}=0.953135$

Table source: drawn by the author

According to the data obtained from the quantitative analysis (Table 5), there is one space in the Webster's Mansion with a maximum connection value of 6 , which is space NO.34 and NO.35, followed by 4 , with 14 spaces. The space permeability is good and relatively high. Similar, the next step is to analyze the node space. 
Table 5: Partial parameter table of Webster's mansion space system at node B

\begin{tabular}{|c|c|c|c|c|c|c|c|}
\hline $\begin{array}{c}\mathrm{Re} \\
\mathrm{f}\end{array}$ & $\begin{array}{c}\text { Choic } \\
\mathrm{e}\end{array}$ & $\begin{array}{c}\text { Connectivit } \\
\mathrm{y}\end{array}$ & Control & $\begin{array}{c}\text { Integration } \\
{[\mathrm{HH}]}\end{array}$ & $\begin{array}{c}\text { Integration }[\mathrm{HH}] \\
\text { R3 }\end{array}$ & $\begin{array}{l}\text { Mean } \\
\text { Depth }\end{array}$ & $\begin{array}{c}\text { Mean Depth } \\
\text { R3 }\end{array}$ \\
\hline 31 & 1517 & 3 & $\begin{array}{c}0.6666666 \\
9\end{array}$ & 1.0464836 & 1.6249448 & 4.4705882 & 2.4166667 \\
\hline 34 & 1829 & 6 & 2 & 1.1225915 & 2.0876319 & 4.2352943 & 2.2333333 \\
\hline 35 & 1703 & 6 & 1.6666666 & 1.0420681 & 2.062937 & 4.4852943 & 2.1851852 \\
\hline 51 & 706 & 4 & 1.1666666 & 1.0420681 & 1.7812788 & 4.4852943 & 2.3199999 \\
\hline 55 & 1129 & 4 & 1.0833334 & 0.90465254 & 1.7909094 & 5.0147057 & 2.2272727 \\
\hline 69 & 0 & 1 & 0.5 & $\begin{array}{c}0.397697 \\
48\end{array}$ & 33334 & 2353 & 2 \\
\hline
\end{tabular}

Table source: drawn by the author

It can be seen from Table 5 that there are two spaces with strong accessibility, followed by 14 spaces with accessibility, which are located on the east side of Webster's Mansion. These spaces have roads, widths and narrows, and present irregular shapes, with the most accessibility. Although the strong space road is narrow, it is also the main spatial hub for the flow of people and occupies an important position in the entire space system. Accessible roads have business functions such as health pharmacies, catering training companies, restaurants, gourmet food and Sanwa bicycle shops. The outside is Cuiqian North Road, so there is a lot of people flow, and the internal and external forms have a close connection. Affect the flow of some people in this village system.

It can be seen from the table that the area with the highest global integration degree is NO.34, with a value of 1.1225 , followed by 1.046 , which is regional NO.31, and again the regions with NO.35 and NO.51, both with a value of 1.042, with the highest local integration degree. The area is No. 34, followed by No. 35, No. 55 and No. 51, which coincide with the global integration degree. The areas are all on the east side of the Webster's Mansion, indicating that the space has a large amount of people.

It can be seen from the table that the global average depth of space NO.69 is 10.132, and the local average depth is 2 , which is the highest in the system. The global average depth of NO.34 is 4.2352, and the local average depth is 2.2333, which is the lowest in the system. The depth is shallower, it can be seen that NO.34 is more convenient in the entire space, condensed into more people flow, and the local average depth is in the middle position, indicating that the local average depth is higher, the privacy is strong, and the space is not easy Find it, it takes a lot of steps to reach here, that is, people can reach the NO.34 space only by teaching the space turning point. In the actual investigation, the number of buildings in this area is 4-7 floors, and most of them are self-built buildings by villagers. The spacing between the buildings is relatively dense and the number of households is relatively large. Therefore, there will be more people in the morning and evening (Figure 19-20) . 


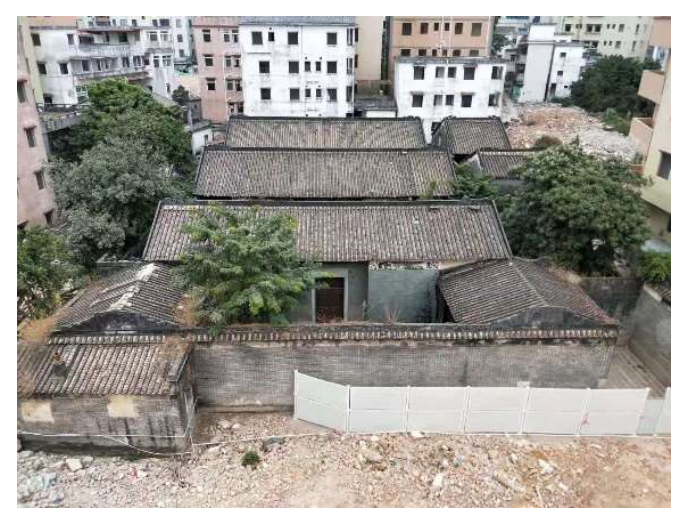

Figure 19 Front of Webster's Mansion

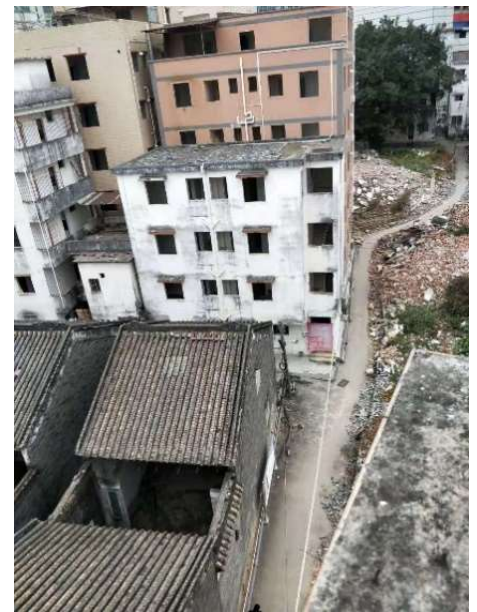

Figure 20 Leading to the back of Cuiwei

Market

Image source: Self-photographed by the author

District

The agglomeration coefficient of the field of view is a judgment on the visual limitation effect of the space boundary. The agglomeration coefficient is judged and distinguished by analyzing the cold and warm colors of the picture. The warmer the color, the higher the agglomeration coefficient, indicating that it interfaces with the surrounding space The less limited the vision, the weaker the occlusion in the system. The colder the color, the lower the value, the lower the aggregation coefficient, and the more obscuration in the system, that is, the more intense the line of sight is oppressed in the space.

As shown in Figure 20, places with a low concentration coefficient of view are more evenly distributed, mostly concentrated in Renheli, Zhongheli, Dunmuli, Yangzixiang, Shengtangli, Yiguli, Nanmingli, Chazi Residential buildings in the alley area. Since each household has a certain number of people, the outdoor roads are relatively narrow and cannot provide enough places for the villagers to stay, so fewer people gather outdoors.

Places with high visual agglomeration coefficients gather in the external public spaces of Road A, Sanwang Temple, Huishan Wugong Temple, Wu Family Ancestral Hall, Jieweng Wugong Temple, Jinhua Temple, Guandi Temple, and Caibo Temple. Residential Nos. 24, 31, and 47 in Guli, Xinlun Guo Gongci, former residence of Yang Meinan, and public space in the northeast of the village.

The left side of road A is Mingzhu South Road, which is the main traffic arterial road in Qianshan area, with dense residential and bustling commerce. On the west side is the Tanzhou area of Zhongshan, where there are more people gathering every day, and there are more night markets in the evening, and there are also on the road. More stalls. The night market can not only attract a large number of people to gather, but also has enough space for people to stay. There are many shops on both sides of road $\mathrm{A}$, and the format function just meets the needs of the villagers in Cuiwei Village for living, eating and learning. Sooner or later, there will be a larger flow of people to increase the vitality of the streets of road A. 
Traditional building types including temples, ancestral halls, public shrines and shrines are important material carriers of folk beliefs in the region. They provide more necessary souvenirs and venues for local intangible culture such as folk beliefs, myths, and religious customs in the region. In the heyday of Cuiwei Village, during the Chinese New Year holidays, a large number of villagers and foreigners would come to the temple to worship and pay tribute to incense. The temple also regularly holds temple fairs, attracting people from inside and outside the village to come to make pilgrimages and pay tribute. When the villagers of Cuiwei get married or their children are full of the moon, they will also put wine outside the temples and ancestral halls, and invite villagers and relatives and friends in the villages to come and drink. There are dozens of pedestals in one swing. The increase in the flow of people increases the agglomeration effect of the outer space of the temples and ancestral halls. Increased vitality of streets and lanes.

Therefore, there will be a large number of people coming to stay outside the temple and ancestral hall. Usually, there will be villagers playing cards and mahjong outside the ancestral hall and residential houses, staying from day to night, so the concentration of sight here is relatively high. According to this characteristic, when combing and analyzing the space of Cuiwei historical block, it is necessary to distinguish the places with different agglomeration coefficients at points and levels.

Therefore, in the process of renovation and reconstruction, the Three Kings Temple, various public temples and ancestral halls in the village are displayed as humanistic and historical spaces. Signs and maps should be set up at the entrance of Menfang to guide visitors to different temples and ancestral halls. , Outside the temple and ancestral halls, there should be signs and introductions of the past and present of ancient buildings for people to watch and understand.

The restrictions on the surrounding space should also be appropriately reduced, and Cuiwei's historical, cultural and cultural characteristics should be integrated into the spatial expression to protect traditions. Temples have very important historical value and reference significance for the research and inheritance of Zhuhai Cuiwei's traditional folklore, folk customs and other intangible cultures.

Observe the visual field intelligibility analysis diagram of the observation block (Figure 21). The scatter points in the figure are dense at first, and the scatter points are more continuous. The light blue does not change in the two-thirds area, and the dark blue area appears obvious. At the back of the fault, it separates two areas. The dark blue area is the space in the middle and east of Cuiwei Historic District. The connection value of these spaces is generally lower than other areas. The dark red area is common. Focus on the upper right, far away from the $\mathrm{K}$ value of the function.

Observing the visual integration map (Figure 20), it is located on the west side of road $A$, indicating that the core area in the village is concentrated on the side of road $\mathrm{A}$, the core area is severely inclined, and the change in connection value is significantly larger than the change in integration. After quantification, it can be concluded that the intelligibility value of the viewing zone is 0.394 , showing a low degree of correlation, indicating that users are more likely to speculate on the structure of the entire network space of the Cuiwei Historic District based on what they see in the local space. difference. 


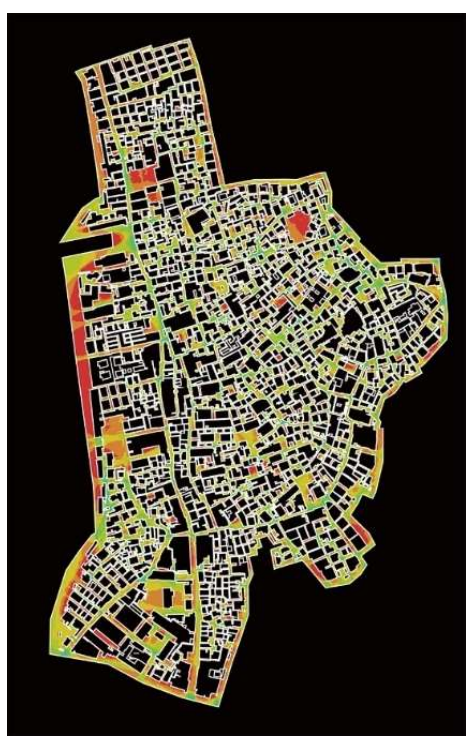

Figure 20 Concentration degree of view field

Data source: drawn by the author

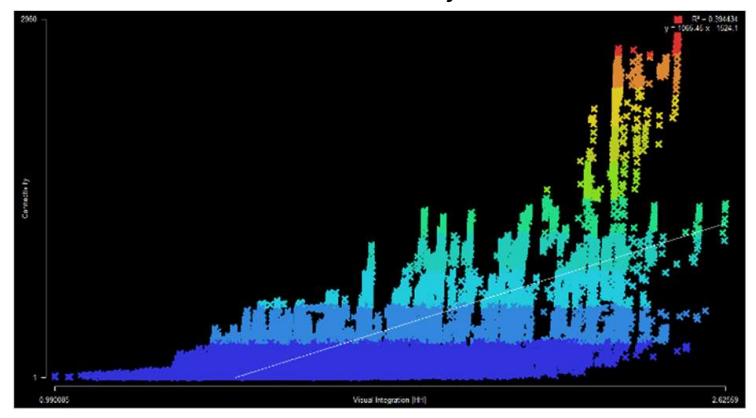

Figure 21 Comprehensible analysis diagram of the view zone of Cuiwei Street (generated by Depthmap)

Data source: drawn by the author

\section{Analysis of Control Value of Horizon and Spatial Features of Historic Lots}

The viewing area control value is roughly the same as the axis control value, and the area of the current neighborhood relative to the total area of the immediate neighborhood is calculated. The viewing area control value helps to highlight the area where the observer can see the larger view of the spatial layout. From Figure 22, it can be seen that the place with a higher value of sight control 4.10 is at the top of road A, the public space of Wugong Temple in Huishan, Wu's Ancestral Hall, Jieweng Wugong Temple, and Sanwang Temple, and It is scattered in the four streets of Dafang Street, Market Straight Street, Cuiwei Street, and Changshui Street. An observation deck or main sign can be set up in these places with high control value of the visual field. The viewing platform not only allows people to watch the structure of the entire village, but also attracts tourists to stop during performances and related themed activities, and enhance the vitality of the space. The main signs set up next to the road can make people understand the direction of the village more clearly, enhance the correlation between people's local perception and overall perception, and people will no longer get lost. So as to attract more people to come to play in the block, and then improve the integration, concentration and comprehensibility of the entire historical streets. 


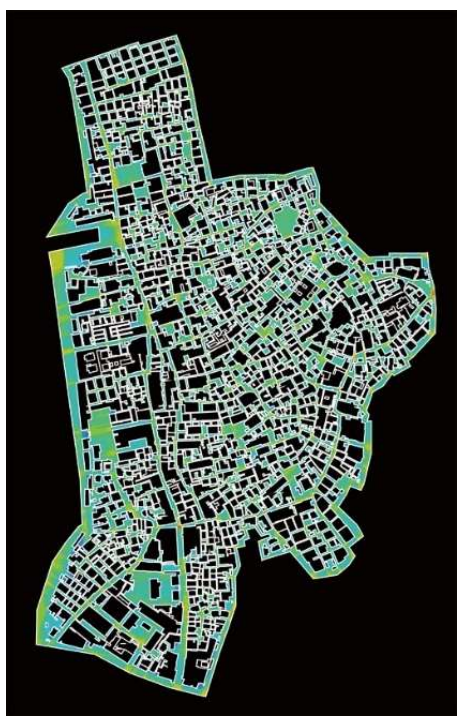

Figure 22 Control Value of View Zone

Data source: drawn by the author

In the analysis of visual connectivity and spatial characteristics of historical locations, the public space is used as the research object, and the closed area of the building is the boundary. It is a measure of whether the spatial connection is close within a certain area, which can reflect the entire historical and cultural block of Cuiwei Village. The spatial accessibility of insiders.

The full-axis analysis includes all the possibilities for the movement of Cuiwei villagers within the Cuiwei site, and is the overall response between the internal crowd activity capacity and the connection of the public space. Import the CAD model of the Cuiwei historical district into Depthmap, and perform a full-axis analysis of the public space, as shown in Figure 25, Mingzhu South Road, Cuiwei Street, Market Straight Street, Dafang Street, Changshui Street, Sanwang Temple, Jinhua Temples, Guandi Temple, Caisi Temple, Rongzhai Wugong Temple, Biyue Wugong Temple, and Meisong Wugong Temple are all good carriers for crowd activities, with a high degree of integration of vision. Superimposing the visual integration degree and the axis, as shown in Figure 23, it can be seen that the highest area within the village is on road A. Because the full axis contains too many elements, although it is quantified, the straight line is artificially drawn, so some errors will inevitably occur. Therefore, it is necessary to analyze and summarize the similar topological relationships, and get the relevant axis to be very good. Summarize the topological relationship of the spatial structure.
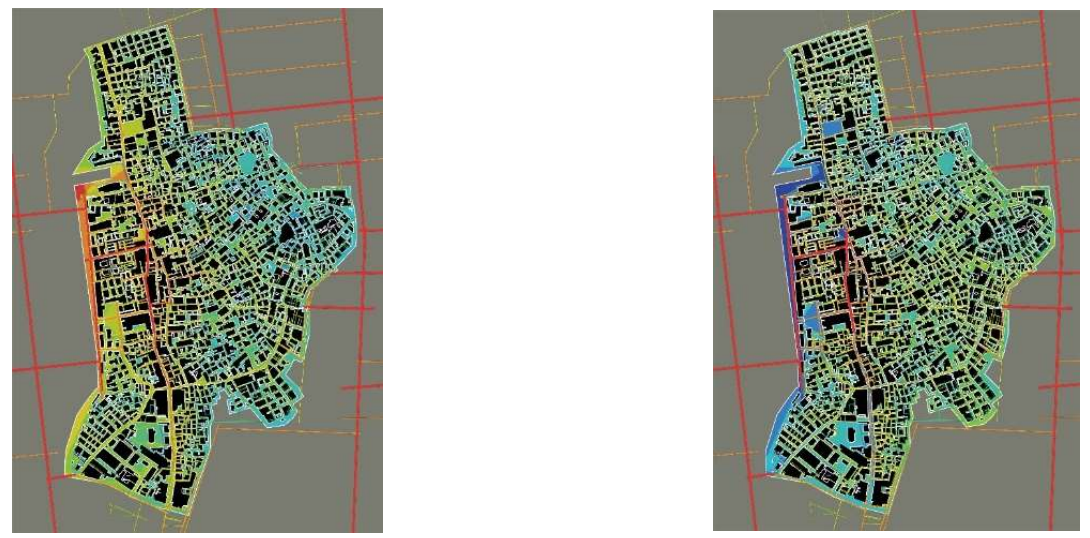
Figure 23: Overlay of visual integration and integration axis of Cuiwei Village

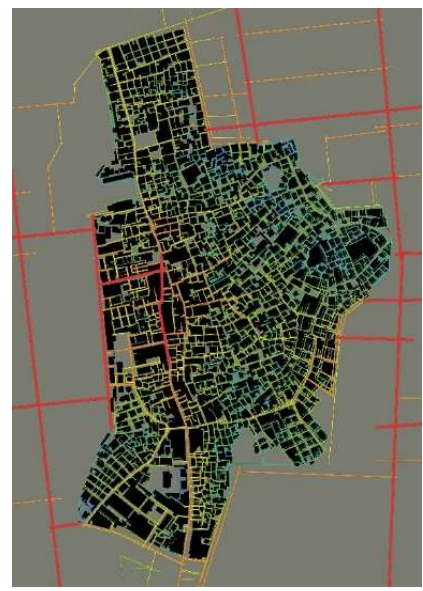

Figure 25 Cuiwei Village Integration Degree Axis Diagram (Visual Depth)
Figure 24: Overlay of visual depth and integration axis of Cuiwei Village

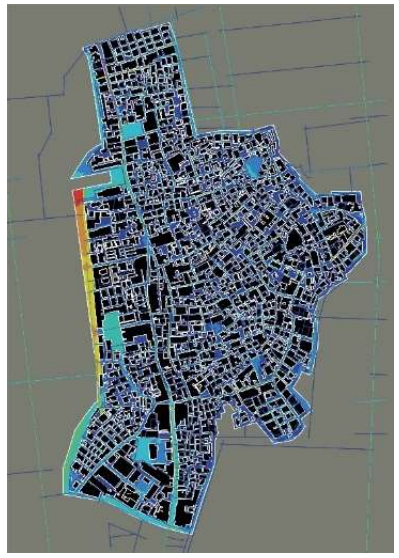

Figure 26: Overlay of visual connection value and connection degree axis of Cuiwei Village

Image source: drawn by the author

Visual depth represents the accessibility between an element and other elements in an open space. The total number of times the line of sight needs to be turned. The lower the value of visual depth, the more people's attention will be attracted. On the contrary, it is not easy to attract people's attention. Superimposing the visual depth map with the minimum axis map, as shown in Figure 81, can reflect the relevant characteristics of the public space of Cuiwei Village. For Cuiwei Village, unlike modern large-scale space, most of the residential buildings inside the village are family living spaces with strong privacy, and the outer space of residential buildings is the focus of people's visual appreciation and spiritual perception.

A visual depth analysis of the historical area reveals that the depth value of the entire area is more uniform in color, indicating that the overall permeability of the block is poor. The color of the road A area is bluer, indicating that the depth value of this area is lower, the easier it is to attract the attention of people walking, and the more people's attention is. People standing at this place can see more than people in other spaces. More space, so that they can have a better grasp of what is happening in more streets and lanes. They can not only observe what is happening to users in the opposite alley, but also can well predict what is happening in their own streets. Various situations. Therefore, for the residents of Cuiwei Village, this kind of space is an environment with a relatively wide field of vision, gathering a certain number of commercial forms, which also proves that they play an irreplaceable role in forming the life of the villagers inside the streets.

Cuiwei Avenue has a high degree of connectivity, with narrower internal streets, strong twists and turns, and more obstructive sight. The visual depth map and the connection degree line are superimposed and analyzed. As shown in Figure 26, the characteristics of the four typical Cuiwei historical district public spaces in Table 6 can be summarized.

Table 6 List of public spaces in Cuiwei Village 


\begin{tabular}{|c|c|c|c|c|}
\hline Type & $\begin{array}{l}\text { High visual } \\
\text { depth, high } \\
\text { accessibility }\end{array}$ & $\begin{array}{l}\text { high visual } \\
\text { depth, low } \\
\text { accessibility }\end{array}$ & $\begin{array}{c}\text { low visual } \\
\text { depth, high } \\
\text { accessibility, low } \\
\text { visual depth }\end{array}$ & $\begin{array}{l}\text { low visual depth, } \\
\text { low accessibility }\end{array}$ \\
\hline $\begin{array}{c}\text { Geospatial } \\
\text { location }\end{array}$ & 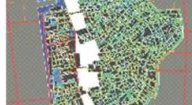 & & & \\
\hline $\begin{array}{c}\text { Typical } \\
\text { representative } \\
\text { area }\end{array}$ & 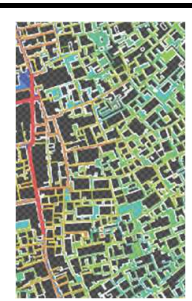 & 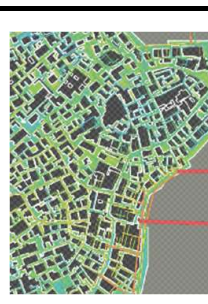 & 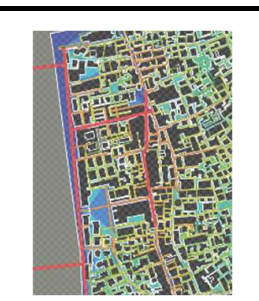 & \\
\hline
\end{tabular}

Image source: drawn by the author

High visual depth and high accessibility: The main traffic arterial road on the west side of Cuiwei Village is Mingzhu South Road, the streets intersecting with Mingzhu South Road are Cuizhu 1st Street and Cuizhu 2nd Street, and the main traffic arterial road on the east side is Cuiqian North Road. The intersecting streets of Cuiqian North Road are Honghu Street and Cuixian Road. The two main arterial roads are both urban branch roads and have high accessibility. The intersections of the two urban branch roads with the secondary streets form a space with high visual depth and high accessibility, and commercial residential buildings along the street outside the village area flourish. There used to be relatively prosperous businesses along the three streets of Dafang Street, Market Straight Street, and Cuiwei Street within Cuiwei Village. In addition to retail stores, health service centers, textile shops, etc., there were more stall facilities along both sides of the street. Carrying specific activities and high accessibility, there are also public shrines, ancestral halls and gate houses along both sides of the street. Therefore, this highly recognizable space can be used as an important part of opening up the inner block in the organic renewal of the street space in the later period, setting up specific signs, and rebuilding more conspicuous gates.

High visual depth and low accessibility: Renheli, Zhongheli, Dunmuli, Yangzixiang, Shengtangli, Yiguli, Nanmingli, Chazixiang have a large number of second-class residential land, distributed More scattered and dense, with a higher visual depth. Due to the development of urban construction at this stage, the area will be demolished in pieces in the future and replaced by a large number of complexes. Most of these buildings are illegal buildings built in disorder in the middle and late stages, blocking the dense road network of the original small neighborhoods. The pattern of streets and lanes results in low overall integration and poor accessibility, making it easy for people to get lost when walking inside. This kind of space is a malformed product of the historical block in the process of urban construction. In the process of renewal, we must consider the ancient buildings in this area, divide and extract them, carry out effective protection, and handle the 
spatial relationship between the new and the old. Ingeniously reduce the impact of large complexes on historical areas.

Low visual depth and high accessibility: A space with low visual depth and high accessibility is formed along Dafang Street, Market Straight Street and Cuiwei Street. Quantitative analysis of the above space syntax shows that the street has a high degree of integration. Among them, the street market has the highest degree of integration in the entire village. Through the sorting of historical data and field investigation and analysis, it can be seen that the road section carries a certain amount of The service facilities in the bustling period carry a large number of service facilities, in addition to the commerce along the street, there are also stall facilities. Although the streets and lanes of Cuiwei Village have a large spatial texture density and the high aspect ratio of the streets and lanes, resulting in poor visibility, it does not affect the vitality of the block in the lot. As a historical heritage in the long-term development and evolution of Cuiwei Village, this type of space is a space for the traditional lifestyle of Cuiwei villagers and has a good bearing role. It is of great significance in the historical block, and the protection value is relatively high. There are many ancient buildings left along the sides of the street. The protection and organic renewal should be emphatically considered, which can play an important role in the revitalization of the street.

Low visual depth and low accessibility: Low visual depth and low accessibility are more common in historical blocks. For Cuiwei historical blocks, the streets are narrow and winding, and the spatial integration and comprehensibility are low, because it is located in Cuiwei Village In the corner area, there is a certain degree of communication with the outside, so the visual depth is low. Due to the large number of illegal buildings in the block and the disorderly erected electric wires, the road network system in the whole area of the village is broken, and the accessibility is low. During the renewal process, the space system of streets and lanes should be dredged, which is the main purpose of the renewal of Cuiwei Historic District. To sum up, as a historical block, Cuiwei Village not only has a relatively weak position in the urbanization process of the entire Qianshan area, it has become more prominent over time, and it is gradually covered by various types of construction land, making road fragmentation more serious. . However, Cuiwei Village is the largest village in Zhuhai, and it is located in the Qianshan area. The city rail Pearl Station is located on the northwest side, and the Tanzhou area on the west side is the Zhongshan Tanzhou area. The location advantage is relatively obvious, so the carrying capacity is relatively strong, and it will be greatly promoted after the renovation. The economic development of the Qianshan area has driven the surrounding businesses and attracted more merchants to settle in. There was a large number of second-class building land in the Cuiwei Historic District, and it will be re-rectified during the renovation process. The streets and lanes have a deeper spatial scale. Except for the direction along Dafang Street and Market Straight Street to Cuiwei Street on the west side, the spatial integration is Better, the overall permeability is poor, lack of perspective and the creation and utilization of public space, it is more difficult to attract the flow of tourists and foreign residents, resulting in poor mobility. Isolation from the outside world for a long time will eventually lead to poor historical continuation and undertaking. 


\section{Analysis of Village Traditional Architecture}

The buildings in the ancient villages in the Guangfu area adopt the plane shape of the triple courtyard. The small lanes formed between the buildings are called "li", and the gates of each house open on the side to connect with the lanes. There is a wide square in the front of the building complex, which is mainly the local sun valley area. The street space is crisscrossed, forming a richer spatial form. The climate in Zhuhai is hot, with frequent wind and rain, and has extremely high requirements for ventilation. According to the local climate conditions, the building plan is designed with features such as ventilation, sun protection, and good moisture resistance.

\subsection{Webster's Mansion}

Considering the representativeness, the inner space syntactic analysis of the architectural courtyard selects the Webster's Mansion and the Three Kings Temple, and conducts a meso-micro scale analysis of them. The current characteristics of the mansion are more distinct, and the main hall axis and the courtyard center axis together form a symmetrical pattern. The single building is more obvious in scale and volume, reflecting a strong family culture. It pays great attention to the use of materials and the detailed description of the structure, which creates a strong visual impact in height, material, structure and color. The detailed components are rich in themes, reflecting the strong characteristics of Webster's culture. There are tall trees outside the courtyard, and most of the greenery in the courtyard is potted plants with abundant varieties (Figures 27-34).

Taking Webster's Mansion as the center and the surrounding buildings of about $45 \mathrm{M}$ as the radius, first process it in CAD, then import it into Depthmap, and quantify it. It can be concluded that the area with the highest integration degree of view passes through the end of Dunmuri, and They are distributed on the east and south side of the mansion, and the higher areas are mainly distributed on the east and west sides of the mansion. The rest of the buildings are in a cool tone, indicating a low degree of integration (Figure 27).

From the perspective of visual depth, the south, west, and east sides of the mansion are all presented in cool colors, and the distribution is relatively even. The lowest area is interspersed with the end of Dongmuli, where the line of sight needs to be turned less frequently. , It is easier to attract people's attention. At the intersection of Cuiqian North Road and Cuixian Road, the external road on the east side of the mansion, there is a large traffic and pedestrian flow. As the city's seventh batch of cultural relics protection units, Webster's Mansion is the only immovable cultural relic within the scope of renewal. Due to disrepair for a long time, the overall structure will be loose and internal components will be damaged to a certain extent. It is protected, retaining the original components and spatial form. In the process of restoration, traditional crafts and materials are used to try to repair the old as old as possible, and it cannot be translated. It is necessary to reproduce the original style of the old building in its original flavor. Partially adopt modern architectural techniques, repair the external facade structure, create public service facilities, fully retain the original elements of historical buildings, respect the wishes of the villagers in operation and development, and make rational use (Figure 27).

Every mansion has a daily activity center, usually halls and patios. The visual depth and the integration of the vision of the mansion are analyzed. The areas with 
higher integration of the vision are concentrated in the middle of the connection between one area and the other. That is the aisle. At the same time, the visual depth of the aisle area is relatively low, which means that the line of sight in this area needs to be turned less frequently, and it is easier to attract people's attention, and the people in the house stay here for a longer time. At the same time, there are two atriums on both sides of the area, which are also a good place for people in the house to enjoy the cool in summer, and it is also an activity center. It means that the flow of people in this space is frequent, the visual depth is high at the corners, the integration is low, and fewer people gather in this place. If the width of the aisle is enlarged, the global integration of the surroundings will be reduced, but the global integration of the middle courtyard It will be greatly improved, the hot spot space has obvious agglomeration effect, generally speaking, it has a centripetal centering space agglomeration effect (Figure 2930).

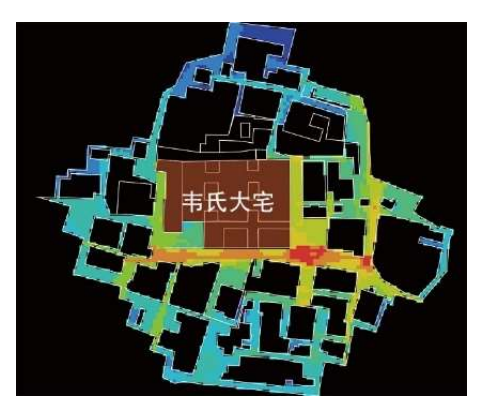

Figure 27 Horizon integration within 45M around Webster's Mansion

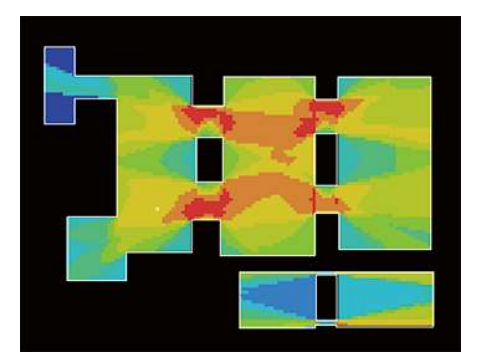

Figure 29 Visual integration of Webster's Mansion

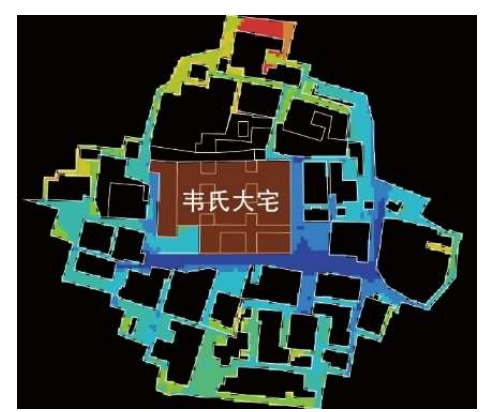

Figure 28 Visual depth within 45M of

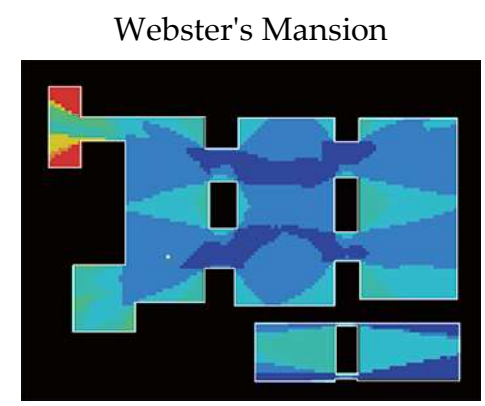

Figure 30 The visual depth of Webster's mansion

Image source: drawn by the author

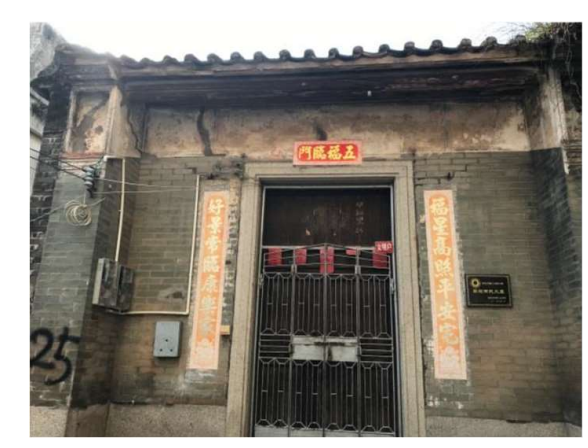

Figure 31 Front view of Webster's Mansion

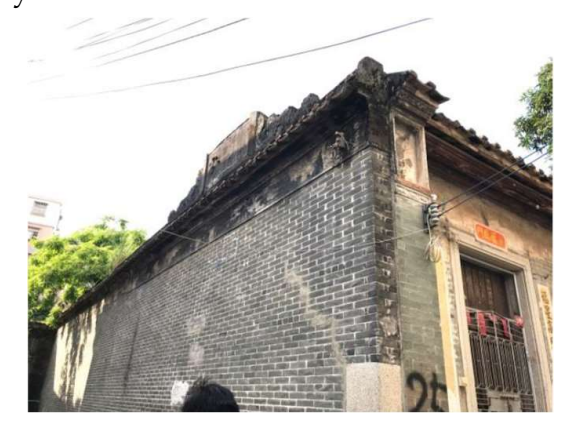

Figure 32 Axonometric view of Webster's mansion

Image source: The author extracted from the summary (2019) of the renewal plan for the renovation project of Cuiwei Old Village, Xiangzhou District, Zhuhai City 


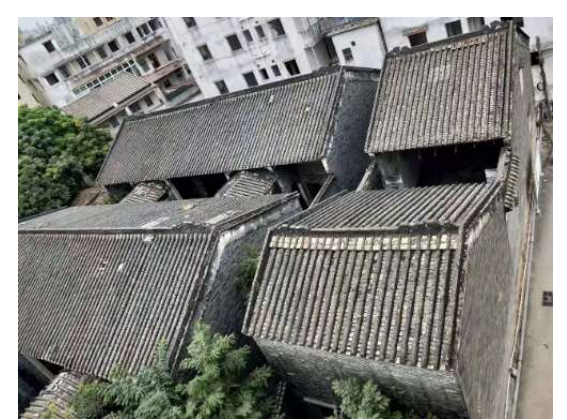

Figure 33: Bird's-eye view of Webster's Mansion from Angle 1

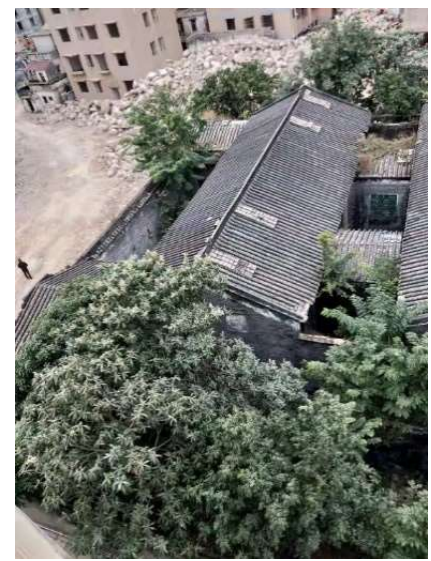

Figure 34 Aerial view of Webster's Mansion

Angle 2

Image source: Self-photographed by the author

\subsection{Three Kings Temple}

First, conduct a microscopic analysis of the Three Kings Temple, and guide the Three Kings Temple together with nearby buildings and roads into the Depthmap to analyze the visual depth and the integration degree of the field of view, as shown in Figures 35-38, it can be concluded that: The external space of Wangmiao has a higher degree of integration and a lower visual depth. The higher the representative agglomeration coefficient of this area, the less visually limited the interface between it and the surrounding space, and the weaker the occlusion in the system. After field investigation and analysis, this area belongs to the public space in the village, that is, the external square space. The square is attached to temples, ancestral halls and other religious buildings. During the Chinese New Year, there are more villagers in this area to celebrate with wine, and gather in the heyday. More people.

The Temple of the Three Kings is not only an important place for the exchange of goods in the market trade, but also a stage for people to watch a play, etc. From the perspective of the protection and renewal of Lingnan buildings, the square space not only simply plays a role of enclosing space, giving people a visual enjoyment, but also ensuring the master-slave coordination relationship between the old and new buildings in the village and the space-time relationship. Continuous action. And because of its low visual depth value, it attracts people's attention. From the perspective of the entire map, Sanwang Temple is on the right side of Cuiwei Street, a historical street, and belongs to a relatively prosperous area in the village. When the future villages are renewed organically, this area should be emphatically used, and infrastructure construction should be improved here. The public space is combined with the micro-space of residents' living, and the more open space is combined with the more private space. Reasonably optimize the space structure, increase entertainment facilities, viewing platforms, plant corresponding landscapes, and embellish the space. Signs are added to the road to guide outsiders to watch, build temporary spaces, and divide the internal plane into functions. Corresponding display panels are arranged on both sides of the wall to introduce the past and present of Cuiwei Village, so as to attract more people to stop and stay. Effectively combine the protection of buildings and squares to stimulate the vitality of the neighborhood (Figure 39-40). 


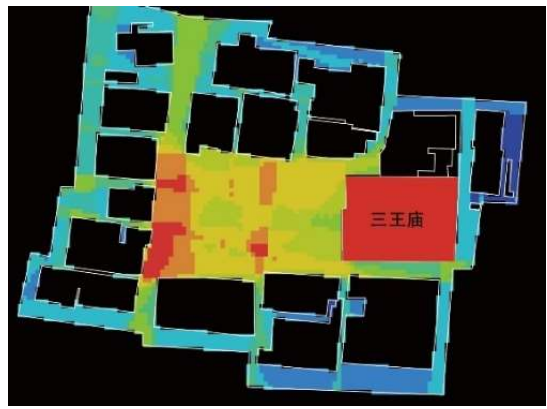

Figure 35 Horizon integration degree of the Three Kings Temple

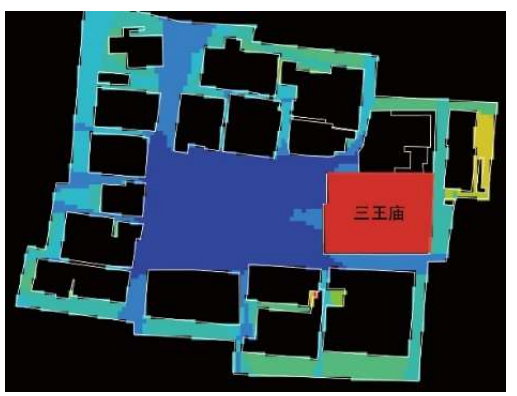

Figure 37 Visual depth of the Three Kings Temple

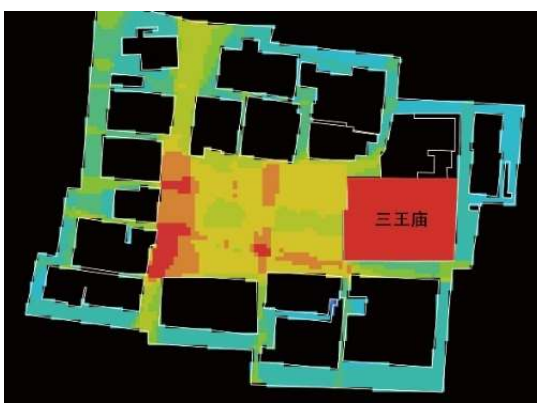

Figure 36 Three-Wang Temple Horizon Integration R3

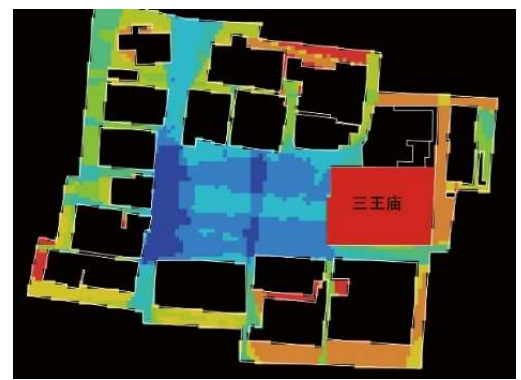

Figure 38 The visual depth of the

Three Kings Temple R3

Image source: drawn by the author

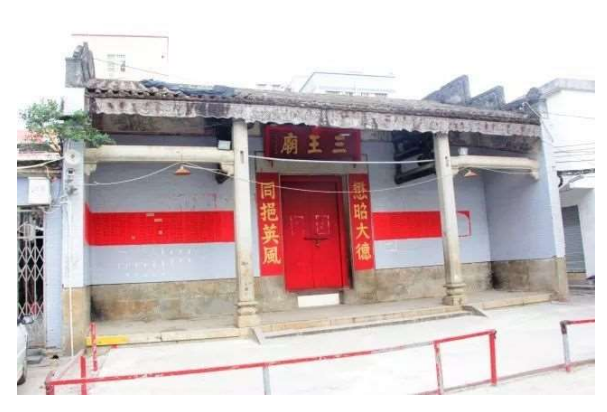

Figure 39 Front of Three Kings Temple

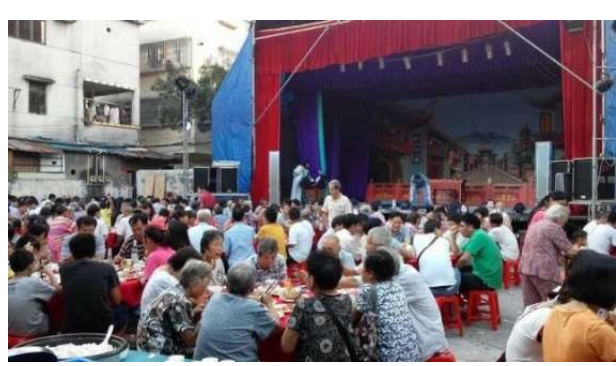

Figure 40 The Heyday of the Three Kings Temple

Image source: https://static.nfapp.southcn.com/content/201711/24/c806817.html

Next, perform a microscopic analysis of the Three Kings Temple, draw the plane outline of the Three Kings Temple on CAD, and import the Depthmap for quantitative analysis, including visual integration and visual depth, as shown in Figures 41-44. It can be found that the visual integration is higher and the areas with lower visual depth are concentrated in the two corridors. Among them, the left corridor has higher visual integration and the areas with lower visual depth are concentrated at the entrance of the corridor. After field investigation and analysis, it can be found that there are incense sticks hanging from the top of the left and right corridors, there is a statue of gods on the left at the end of the left corridor, and Guanyin statues are seen at the end of the right corridor. People often gather here to worship, and there is also incense in the middle of the patio. altar. Towards the main hall and Toumen, the degree of visual integration gradually increases, and the visual 
depth gradually decreases, indicating that most people will gather in this direction (Figure 45-46).

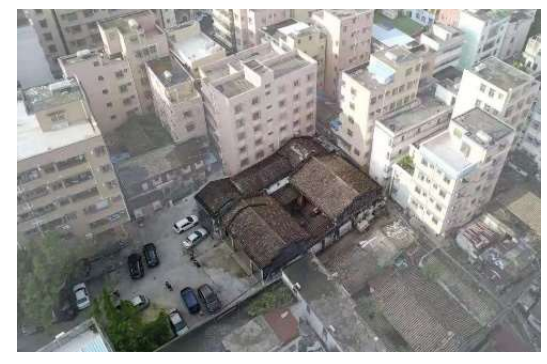

Figure 41 Bird's-eye view of Sanwang Temple

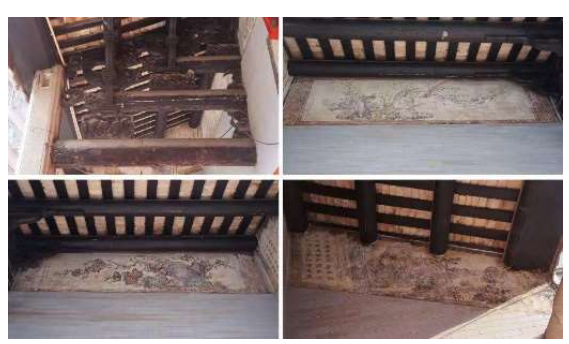

Figure 43 The woodcarving beam frame and wall frieze of the head gate of the Sanwang

$$
\text { Temple }
$$

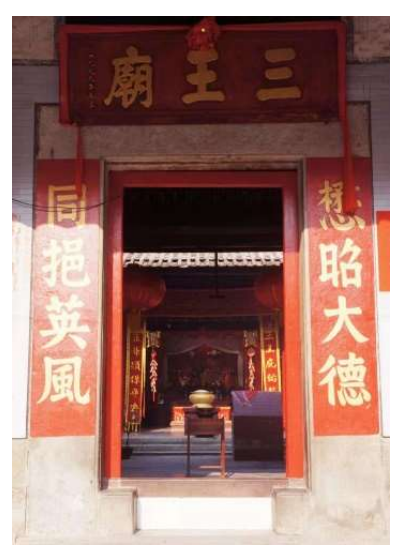

图 42 三王庙门口 Figure 42 The entrance of Sanwang Temple

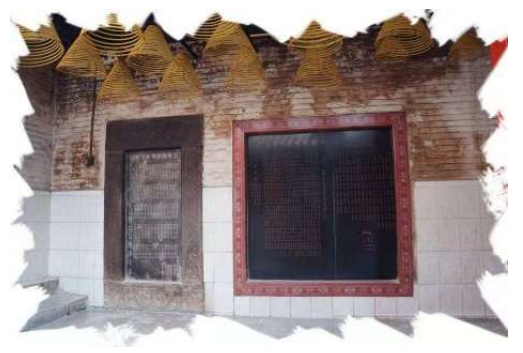

Figure 44 The inscription in the Sanwang Temple (the left side is the "Inscription on the Newly-built Auxiliary House of the Sanwang Ancient Temple")

Image source: WeChat official account of Zhuhai Natural Resources Bureau

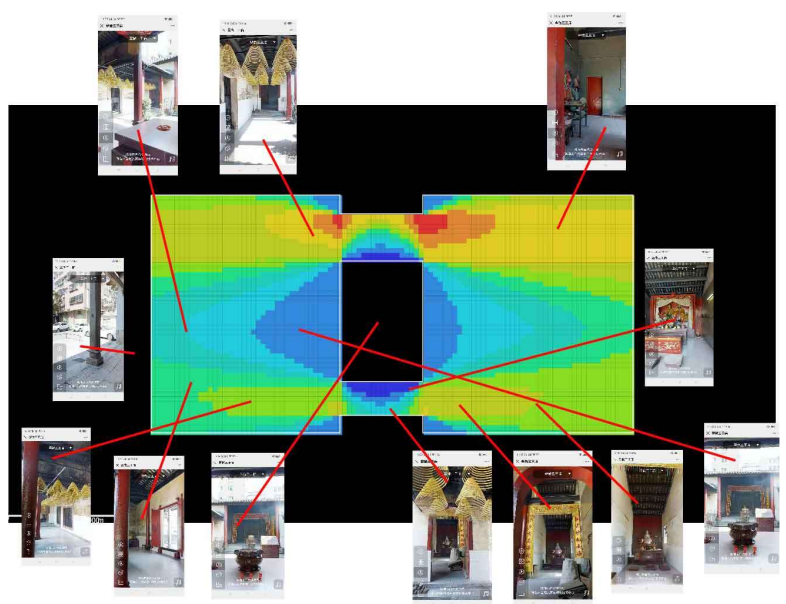

Figure 45 Visual integration of the Three Kings Temple Image source: drawn by the author 


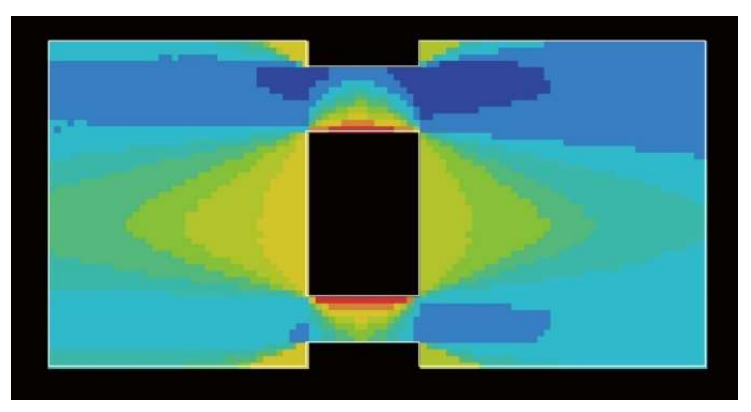

Figure 46 The visual depth of the Three Kings Temple

Image source: drawn by the author

\section{Summary}

With the rapid development of my country's economy, the process of urbanization has gradually accelerated, and a large number of ancient villages have been abandoned and compressed, which has caused serious damage to the original structure of ancient villages. The development of village blocks is closely related to the protection and organic renewal of blocks, the embodiment of commercial value, the connection of internal and external traffic and road networks, and the development of economy. Among them, the spatial syntax is the research and analysis of the spatial form of the historical blocks of the village. To the vital role. Based on the theory of space syntax, this paper analyzes the internal spatial characteristics of the Cuiwei Historic District in the Qianshan area of Zhuhai City under the background of the "Three Old Reconstructions" of the cities in Guangdong Province, and determines the entire village through the distribution and characteristics of the change values in the village. The overall spatial characteristics of the field. Village collaboration is poor, people's recognition in the village space is weak, people cannot use local perception to reflect the overall space, there is a clear interface between the inside of the village and the outside world, the isolation state is more obvious, the local comprehensibility is better, and the global can be understood. The understanding is poor. Although people can also walk out of Cuiwei Village, they are always in a state of confusion and it is difficult to grasp the spatial form of the entire area.

\section{References}

1.Xiangkai Wang.; Jingbo Xie. Spatial Syntactic Analysis of the Streets and Alleys of Guangfu Ancient City. Urban Architecture, 2019, 16(21), 22-23.

2.Xinzheng Wang.; Jiayi Guan. Quantitative analysis of street space in Guyao District of Jingdezhen based on space syntax. 2019, Journal of North China University of Technology, 31(2), pp. 127-133.

3.Yi Yin. Research on the spatial morphology of the famous historical and cultural village of Bailu based on space syntax.2018, Master's thesis, Jiangxi University of Science and Technology, Jiangxi.

4.Quanshui. Research on the spatial characteristics of Kashgar historical and cultural blocks based on space syntax. 2012, Master's thesis, Harbin Institute of Technology, Harbin.

5.Yuwe Chen.; Sun Junqiao. Quantitative Analysis of Streets and Lanes of Historical and Cultural Villages and Towns Based on Space Syntax--A Case Study of Anju Ancient Town in Tongliang, Chongqing. 2019, Journal of Western Human Settlements, (2), pp. 106- 112.

6.Yanhong Jiao. Research on the spatial characteristics of Baoding historical and cultural blocks based on space syntax. 2019, Master's thesis, Hebei Agricultural University, Hebei.

7.Liu Hao.; Zhong Yanfen. A Syntactic Study on the Spatial Forms of Streets and Alleys in Traditional Villages - - Taking Luotian Village in the Ancient Villages of Anyi as an Example. 2019, Urban Architecture, 16(25), pp. 109-112. 